\title{
Revisão: tuberculose genital em bovinos e bubalinos
}

\section{Review: genital tuberculosis in cattle and water buffaloes}

\section{Revisión: tuberculosis genital en ganado bovino y bufalino}

\author{
Alessandra Figueiredo de Castro Nassar; ${ }^{1}$ Eliana Roxo; ${ }^{2}$ Manuel Alberto da Silva Castro Portugal ${ }^{3}$
}

Instituto Biológico. São Paulo, SP, Brasil

\section{Resumo}

Objetivo: Apresentar uma revisão sobre a tuberculose genital em bovinos e búfalos. Fontes Pesquisadas: Foram consultados os acervos das bibliotecas da Faculdade de Medicina Veterinária e Zootecnia da Universidade de São Paulo (FMVZ/USP) e do Instituto Biológico de São Paulo; além da base de dados MEDLINE, cuja pesquisa atingiu um período retrospectivo de 30 anos. Síntese dos Dados: A tuberculose é uma doença de significativa importância econômica, causando grandes prejuízos à pecuária e implicações à saúde pública. $\mathrm{O}$ aspecto zoonótico da tuberculose tem diminuído pela obrigatoriedade da pasteurização do leite. Porém, em alguns países, esse caráter da doença ainda persiste devido ao hábito de se consumir o leite cru e queijos produzidos sem tratamento térmico. Estima-se que $5 \%$ das vacas tuberculosas desenvolvam infecção genital, ocasionando principalmente lesões no útero (metrite), e $1 \%$ a $2 \%$ podem desenvolver mastite tuberculosa. Tuberculose genital nos machos é mais rara, no entanto, pode ocasionar lesões em praticamente todo aparelho reprodutivo. Em búfalos, a incidência de tuberculose é maior do que em bovinos, e as lesões se distribuem por todos os órgãos, incluindo o aparelho reprodutor com lesões de endométrio. Comentários Finais: Estima-se que a prevalência de tuberculose bovina no Brasil seja de 0,9\% a 2,9\%. Contudo, não se caracteriza como uma doença da reprodução, ainda que sua ocorrência não seja tão rara no sistema reprodutivo de bovinos e bubalinos. Pode causar ainda transtornos reprodutivos, como infertilidade e repetições de cio, representando assim uma via pouco comum de transmissão da doença.

Palavras-chave: Tuberculose dos genitais. Mycobacterium bovis. Infertilidade. Bovinos. Búfalos.

'Médica Veterinária. Pesquisadora Científica Nível I. Instituto Biológico. Mestranda pela Universidade de São Paulo. CRMV-SP 13913

${ }^{2}$ Médica Veterinária. Pesquisadora Científica Nível VI. Instituto Biológico. Mestre e Doutora pela Universidade de São Paulo. CRMV-SP 3961

${ }^{3}$ Médico Veterinário. Pesquisador Científico Nível VI (aposentado). Instituto Biológico. Doutor pela Universidade de São Paulo. CRMV-SP 129 


\section{Introdução}

A tuberculose foi reconhecida em animais primeiramente como doença causada por um agente infeccioso com transmissibilidade a coelhos a partir de material humano aos animais. Foi descrita pela primeira vez por Villemin em 1865, $\left(\operatorname{apud}^{11}\right)$, mas foi Robert Koch ${ }^{11}$ quem, em 1882, descobriu o agente infeccioso, corando-o pela fucsina-anilina e, em 1884, isolou-o em meio de cultura, reproduzindo experimentalmente a doença em animais de laboratório. ${ }^{1}$

A tuberculose é uma doença de significativa importância econômica, determinando grandes perdas na criação de animais, principalmente bovinos, o que condiciona gastos elevados na área de saúde pública para seu controle.

A prevalência da tuberculose humana de origem animal tem diminuído significativamente em países onde a pasteurização do leite é norma obrigatória e também em virtude das campanhas visando ao controle e erradicação da zoonose nas propriedades de bovinos e bubalinos de exploração leiteira. Entretanto, em países em desenvolvimento ainda persiste o hábito de se consumir o leite cru, ou preparar derivados com leite não fervido. ${ }^{2}$

Com o surgimento da síndrome da imunodeficiência adquirida (AIDS) em humanos verificou-se um crescimento muito grande do número de casos de tuberculose, bem como o aparecimento de cepas multidroga-resistentes devido a tratamentos inadequados e incompletos..$^{3-5}$

A tuberculose ainda mata mais de três milhões de pessoas no mundo a cada ano e, em países do Terceiro Mundo, são diagnosticados mais de dez milhões de novos casos anualmente. ${ }^{6}$

$\mathrm{Na}$ atualidade, um dos principais receios é que a tuberculose venha a se tornar uma doença incurável como resultado do aparecimento de cepas resistentes do agente bacteriano às drogas antituberculosas. ${ }^{7}$

\section{Histórico da Doença}

A tuberculose é uma das doenças transmissíveis mais antigas, afetando o homem desde sua préhistória. ${ }^{8}$ Achados de lesões em ossos humanos préhistóricos, na Alemanha, sugerem a existência da tuberculose há 8.000 a.C. Múmias do templo de Ramsés, 3.000 a.C., apresentavam lesões de tuberculose óssea (Mal de Pott). Hipócrates mencionou uma doença pulmonar, cujo curso era similar ao da tuberculose pulmonar. Por sua vez, Aristóteles afirmava que a tuberculose era contagiosa, e que a doença tinha grande incidência no povo grego. ${ }^{9}$

A presença de tuberculose óssea foi verificada em um fóssil de búfalo americano (Bison bison), que viveu a mais de 17.000 anos, sendo confirmada pela técnica de detecção de DNA (ácido desoxirribonucléico). Nessa amostra, caracterizou-se a semelhança com o Mycobacterium tuberculosis, porém, com algumas seqüências de DNA a menos, que podem ter sido perdidas com a evolução da espécie. Assim, pode-se dizer que o $M$. bovis pode descender do $M$. tuberculosis ou de um ancestral comum. ${ }^{10}$ Villemin, em 1865, apud $^{11}$ ) descobriu que as tuberculoses humana e bovina podiam ser transmitidas a cobaias e coelhos por inoculações, mas sem a certeza de ser uma doença infecciosa. Somente em 1882, Robert Koch $^{11}$ conseguiu isolar o bacilo, denominando-o de Tuberkelbacillen (bacilo da tuberculose). Por muito tempo, acreditou-se que existia apenas um bacilo da tuberculose que acometia homens e animais. Entretanto, Smith, em 1898, $\left(\right.$ apud $^{12}$ ) observou a diferença entre os bacilos. O bovino apresentava um tamanho menor, com crescimento lento em meio de cultivo, sendo mais virulento para os animais de laboratório, quando comparado ao bacilo humano. ${ }^{12,13}$

McFadyean, em 1902, $\left(\right.$ apud $\left.^{13}\right)$ declarou que a causa de tuberculose intestinal em crianças na Escócia foi devida a "tubérculos bovinos" de vacas leiteiras, mas somente Ravenal, em 1902, (apud ${ }^{14}$ ) obteve a primeira prova definitiva da transmissão da tuberculose bovina ao homem por ingestão de leite não fervido. ${ }^{13,14} \mathrm{Em} \mathrm{1911,} \mathrm{chegou-se} \mathrm{à} \mathrm{conclusão}$ 
definitiva de que bovinos tuberculosos representavam risco para a saúde pública e algo precisava ser feito, já que os dados das doenças nos animais eram alarmantes. ${ }^{12}$

\section{Agente Etiológico}

O agente etiológico da tuberculose pertence ao gênero Mycobacterium que contém mais de 70 espécies, das quais pelo menos 22 podem causar doença no homem e nos animais. São bacilos imóveis, não esporulados, aeróbios, não encapsulados e não flagelados, medindo de 0,3 a $0,6 \mu \mathrm{m}$ de largura por 1 a $4 \mu \mathrm{m}$ de comprimento. São considerados bacilos álcool-ácido resistentes, visto que não sofrem descoloração com aplicação de solução álcool-ácida, quando corados a quente pela fucsina. ${ }^{15,16}$ Entre as espécies causadoras de doenças em homem e animais, destacam-se as incluídas no complexo Mycobacterium tuberculosis, que compreende: Mycobacterium tuberculosis, $M$. bovis, $M$. africanum (isolado de humanos na África equatorial); M. microti (patogênico para ratazana - Microtis agrestis) e $M$. canettii, raramente patogênico para o homem. ${ }^{15-18}$ Ambos, $M$. tuberculosis e $M$. bovis, são patogênicos para o homem. ${ }^{4}$ Segundo Cousins et al., ${ }^{19}$ mais uma espécie foi descoberta, M. pinnipedii, isolada de focas e leões marinhos, mas pouco se conhece de seu potencial patogênico para humanos e outros animais.

\section{Patogenia}

A principal via de transmissão da tuberculose nos animais, particularmente nos bovinos, é a via aérea, mas também pode ocorrer a infecção pela via digestiva. Inicialmente ocorre um foco de infecção pulmonar com extensão das lesões aos linfonodos pulmonares, estabelecendo-se o "Complexo Primário". Nas infecções aerógenas, esse complexo pode ser perfeitamente observado, mas nas infecções via digestiva, geralmente, ele se torna incompleto e, em pouco tempo, com a regeneração da mucosa entérica, persiste somente a lesão no linfonodo. ${ }^{2.9} \mathrm{Os}$ bacilos podem permanecer nos linfonodos ou nos granulomas tuberculosos por longos períodos, multiplicando-se ou permanecendo sob a forma "dormente". Por intermédio de uma reinfecção exógena ou endógena (pela recrudescência da lesão), a lesão se torna necrosada, podendo atingir os tecidos vizinhos e se disseminar por outros órgãos. ${ }^{20,21} \mathrm{~A}$ disseminação se faz via linfo-hematógena, e o agente se distribui por todo o organismo do animal, esse fenômeno é denominado "generalização precoce". Esse processo leva à formação de diversos tubérculos de pequeno tamanho, firmes, rodeados por halos eritematosos de inflamação ativa e com tendência à rápida caseificação central, podendo ser encontrado em vários órgãos. ${ }^{9}$

A tuberculose também pode ser transmitida por eliminação do bacilo no leite, nas fezes, na urina, em secreções vaginais e uterinas, e pelo sêmen, além daquela por via aérea clássica representada por corrimento nasal e expectoração. ${ }^{22-24}$

Estima-se que 5\% das vacas acometidas por tuberculose desenvolvam a forma genital, ocasionando lesões no útero, com metrite, e $1 \%$ a $2 \%$ podem desenvolver a mastite tuberculosa. ${ }^{2}$

Na revisão sobre tuberculose genital em bovinos publicada por Williams, ${ }^{25}$ em 1918, essa doença em machos é rara. Entretanto, quando presente, causa lesões nodulares no nível dos testículos, epidídimo, cordão espermático, provocando hidrocele e, excepcionalmente, formação de tubérculos no pênis e saco prostático. O pênis, quando comparado a outras partes do aparelho reprodutivo masculino, é o órgão reprodutivo mais comum no qual se podem encontrar lesões. Elas geralmente se restringem ao pênis, sem comprometerem a uretra, o corpo cavernoso, o prepúcio e os linfonodos adjacentes.

A tuberculose peniana pode se manifestar por presença de nódulos na camada mucosa ou na submucosa, com erupções cutâneas de aspecto ulcerativo, formando nódulos duros, de aspecto fibroso, com conteúdo caseoso, que podem supurar. Lesões extensas e confluentes provocam edema e enduração. A lesão testicular geralmente é 
precedida de lesão no epidídimo. A possibilidade de infecção do óvulo diretamente pelo sêmen contaminado foi considerada duvidosa por Nocard e Lelainche (1903). ${ }^{26}$

Segundo Vallée e Panisset (1920), ${ }^{27}$ as lesões tuberculosas podem estar presentes nos testículos na forma de protuberâncias duras e arredondadas, principalmente junto ao epidídimo, com invasão do testículo e condão testicular, inflamação da serosa, presença de nódulos na superfície da glande, hidrocele, e fistulação abscedante. Raramente aparecem lesões granulomatosas na porção anterior do pênis, mas a tuberculose no prepúcio é mais comum.

Petisca, em 1969, ${ }^{28}$ citou a ocorrência de lesões caseosas, sugerindo ser tuberculose. Esta acometia todo o tubo seminífero, porém, sem comprometimento dos linfonodos adjacentes.

Em 1986, conforme relato de Roxo,* quatro amostras de sêmen bovino para inseminação artificial foram submetidas a cultivo. Delas, foram isoladas três amostras de micobactérias de crescimento rápido, das quais duas eram escotocromogênicas. Por sua vez, Niyas Ahmed et al., ${ }^{29}$ em 1999, detectaram DNA de Mycobacterium bovis em um touro dentre três analisados pela técnica da reação em cadeia da polimerase (PCR). Esse método de PCR já pode ser considerado como uma ferramenta que permitará identificar rapidamente os animais infectados, evitando a transmissão da doença para um grande número de fêmeas, já que o Mycobacterium spp permanece viável mesmo em condições de armazenamento do sêmen.

Segundo Manninger ${ }^{30}$ (1973), vários autores relataram que quando o macho apresenta a tuberculose genital, esta pode ser transmitida no ato sexual. Todavia, em fêmeas acometidas por tuberculose vulvar ou vaginal, a contaminação poderá ocorrer a partir das fezes contaminadas, quando da ocorrência de tuberculose intestinal, não sendo pois exclusiva a infecção pela monta natural.

\footnotetext{
* ROXO, E. Comunicação pessoal. São Paulo: Instituto Biológico, 1986
}

Nocard e Leclainche ${ }^{26}$ citam a contaminação de diversas vacas a partir de um touro com tuberculose peniana, as quais 8 a 14 dias após a cobertura apresentaram mucosa vaginal e vulvar hiperemiadas e espessadas. Essas alterações por corrimento purulento amarelado são acompanhadas de movimentos frequientes da cauda. Após 10 a 13 dias, parte dos nódulos formados descamaram e cicatrizaram espontaneamente, porém, alguns persistiram, tomando aspecto caseoso, e uma das vacas desenvolveu tuberculose generalizada. Esses autores citam ainda que a tuberculose na vulva pode ou não estar associada à tuberculose uterina, iniciando-se por uma tumefação dos lábios vulvares. Após algumas semanas, evolui com hiperemia e enduração, com numerosos pequenos nódulos na superfície mucosa, que podem ser confluentes, provocando corrimento mucopurulento amarelado e ulcerações muito doloridas. Geralmente, na comissura labial superior, com enfartamento do linfonodo mamário.

No útero, a tuberculose se manifesta como uma metrite purulenta crônica com corrimento mucopurulento esbranquiçado persistente após o parto, que pode tornar-se escuro e com estrias de sangue, levando à infertilidade e comportamento ninfomaníaco. O colo do útero geralmente permanece fechado ou permite passagem de pequeno corrimento, com formação de massa consistente preenchendo um ou os dois cornos uterinos. À palpação retal, pode-se observar hiperplasia dos linfonodos internos, dificuldade em localizar a bifurcação dos cornos uterinos que se assemelham a cilindros duros e, em um terço dos casos, as trompas estão espessadas como um cordão ondulado, duro e espesso. Nos ovários pode aparecer aumento de volume duro, com presença de massa caseosa ou calcificada. $\mathrm{O}$ exame bacteriológico da secreção vaginal pode permitir o isolamento do agente. Segundo Nocard e Leclainche, ${ }^{26}$ a tuberculose peritonial parece freqüentemente afetar o útero pelas trompas. A transmissão transplacentária da tuberculose bovina é muito rara, pois as porções materna e fetal da placenta são unidas por um tecido conjuntivo frouxo, pouco permeável, que, quando íntegro, não permite a passagem do bacilo. A tuberculose uterina pode levar à infecção do feto, 
penetrando pela veia umbilical, ganhando os cotilédones após a destruição do córion e produzindo lesões no fígado.

As lesões podem ser encontradas em qualquer parte do aparelho genital feminino quando da infecção por Mycobacterium bovis. ${ }^{28}$ Quando há casos de tuberculose vaginal, normalmente ocorre enfartamento dos linfonodos perineais. Na tuberculose uterina, a suspeita clínica se concentra no encontro de alterações reprodutivas, como: infertilidade, abortamentos, repetições de cio e presença de corrimentos vaginais mucopurulentos com grânulos de coloração amarelada. Os ovários são raramente acometidos em bovinos, mas também podem mostrar-se aumentados de volume e endurecidos. O útero é o órgão do aparelho reprodutivo feminino mais freqüentemente acometido, porém, pode-se observar lesões em menor grau em outros órgãos, como ovários, trompas e vagina, como mostrado nas Figuras 1 a $3 .^{25}$

A tuberculose congênita, transmitida via transplacentária, considerada rara, foi observada por Myers, ${ }^{31}$ em um bezerro, em 1914, após o $5^{\circ}$ dia do nascimento, que apresentou reação positiva ao teste tuberculínico e, ao exame post-mortem, constatouse a presença de tuberculose generalizada. Roxo et al. ${ }^{32}$ também observaram tuberculose generalizada em um bezerro oriundo de um rebanho leiteiro comprovadamente tuberculoso, que morreu aos três meses de idade. Esse fato, sugeriu como possibilidades de transmissão, nesse caso, as vias transpla-centária e respiratória ao contato com a mãe e outros animais infectados, ou ainda a via digestiva pelo consumo de leite e colostro contaminados. A tuberculose mamária, também considerada pouco corrente, foi descrita por Nocard e Leclainche, ${ }^{26} \mathrm{em}$ 1903, como sendo mais freqüentemente observada em um único quarto, preferencialmente o posterior $\mathrm{e}$ raramente dois dos quartos eram afetados. Manifestase inicialmente como uma tumefação indolor difusa ou localizada, sem afetar o leite ou a produção leiteira, que progride para enduração, com nódulos subcutâneos. Pode evoluir para mastite hipertrófica esclerótica da glândula, formando uma massa dura e fibrosa, podendo apresentar coleções purulentas, semelhantes à actinomicose. Por fim, leva à queda da produção leiteira.

Em animais abatidos provenientes da Região Centro-Sul do Brasil, no ano de 1917, foram observadas $0,03 \%$ de lesões sugestivas de tuberculose no aparelho reprodutivo. ${ }^{33}$

Em uma pesquisa realizada com 12 mil vacas na Suécia, em 1925, dos 4,2\% de animais com tuberculose bovina, as lesões estavam presentes no trato genital em $11,36 \%$. Na Inglaterra, Burrow et al., ${ }^{34}$ em 1937, observaram uma incidência de tuberculose genital em $23,75 \%$ de um total de 82 vacas. Segundo relato de Deshpande, ${ }^{35}$ foi constatada por Cembrowcz em 1946, uma porcentagem de 5,8\% de tuberculose genital em um total de 730 vacas estudadas.

No ano de 1976, na Uganda, foi realizado um estudo preliminar de distúrbios reprodutivos em vacas e verificou-se que das 298 vacas não prenhes analisadas, nove $(3,02 \%)$ apresentavam lesões de tuberculose nos órgãos genitais. ${ }^{36}$

Em um inquérito realizado em 1.835 animais ao abate, Biolatti et al., ${ }^{37}$ em 1982, relatam que aproximadamente metade desse total apresentava lesões sugestivas de tuberculose bovina, dos quais $4 \%$ eram fêmeas. Cinco delas foram analisadas por possuírem lesões aparentemente recentes no útero (intra e extracaruncular), trompas, ovários e serosas. Apenas não foram observadas lesões na vagina.

Roxo e colaboradores,$^{38} \mathrm{em} 1993$, encontraram em um lote de 18 novilhas, 14 positivas para tuberculose pelo teste simples caudal e, ao sacrifício, foram observados quatro animais com lesões generalizadas, envolvendo pulmões, fígado, linfonodos e aparelho reprodutivo (útero e ovários). Essas novilhas infectadas eram mantidas como receptoras de embrião em um rebanho elite de corte, o que configurou um importante fator de risco de introdução da doença na propriedade, quando da aquisição de animais de procedência não investigada, sem teste tuberculínico prévio. 


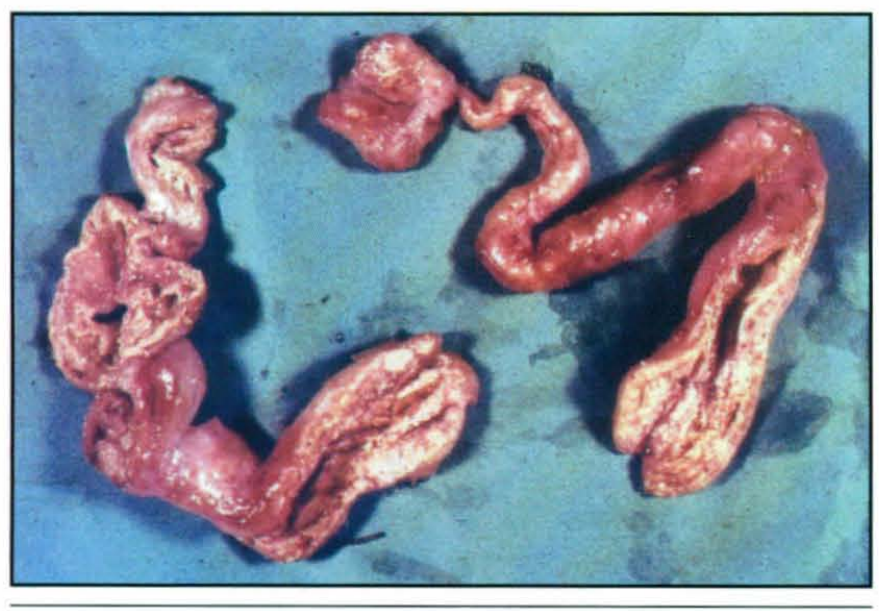

Figura 1 - Trompas e ovários bovinos com lesões tuberculosas

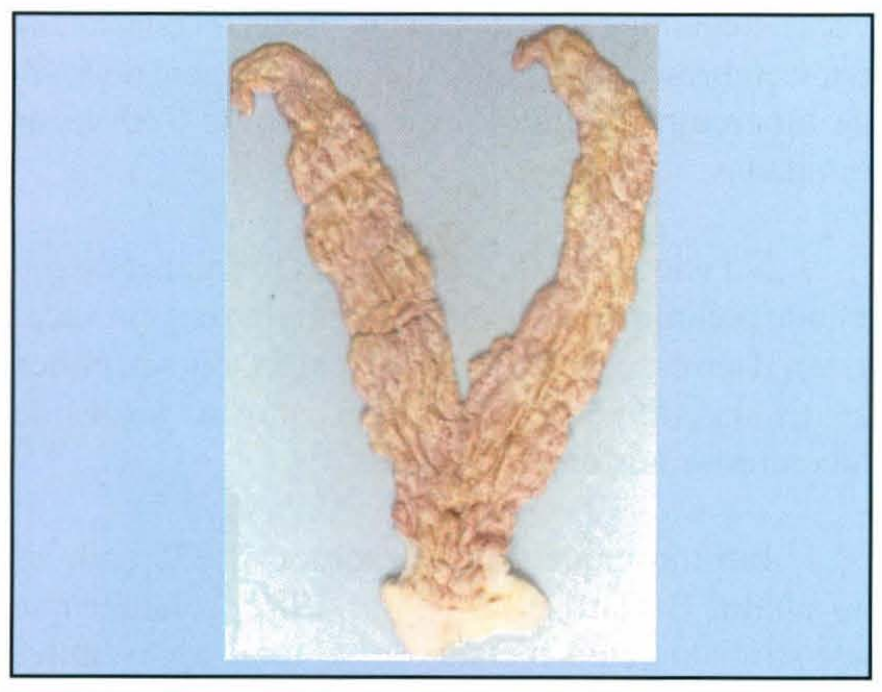

Figura 2 - Útero e ovários bovinos com lesões tuberculosas

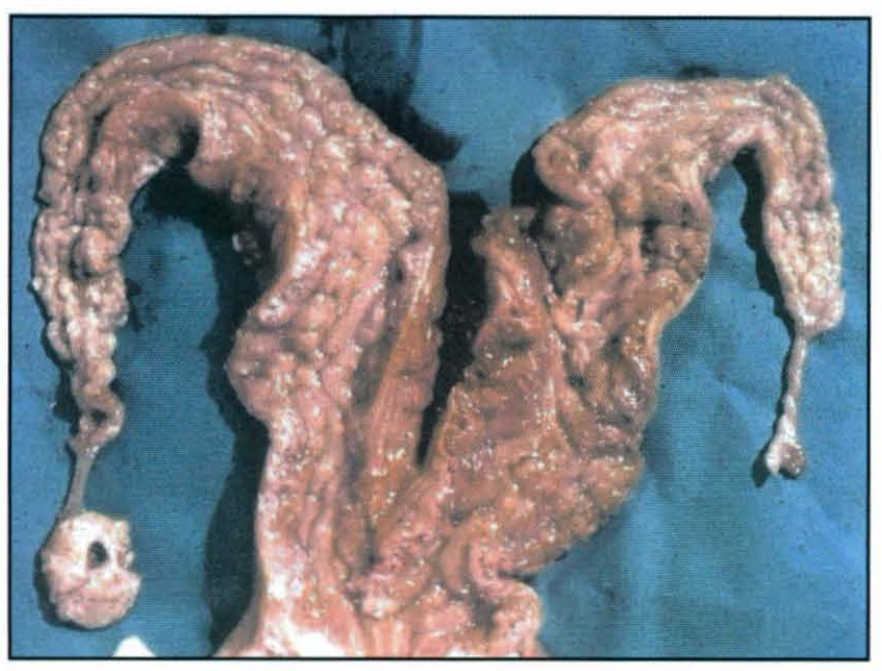

Figura 3 - Útero e ovários bovinos com lesões tuberculosas e endométrio edematoso e hiperêmico
Deshpande et al., ${ }^{35}$ em 1966, relataram que a incidência da tuberculose nos búfalos era maior do que em bovinos. Dos 44.519 bovinos testados, somente $4,7 \%$ apresentaram reação positiva, enquanto que dos 40.201 búfalos testados, $13,8 \%$ dos animais apresentaram reação positiva. Nesses positivos, foram encontradas lesões em vários órgãos, incluindo o aparelho reprodutor com lesões no endométrio.

Alguns autores descrevem lesões tuberculosas em búfalos. Polding e Lall, ${ }^{39}$ em 1945, relataram incidência de tuberculose genital em búfalas, com lesões localizadas principalmente nos ovários, e foram raros os casos de cervicite. Deshpande et al. ${ }^{35}$ também citam lesões uterinas em búfalos ao abate. Mandal e Singh, ${ }^{40}$ em 1975, descrevem caso de tuberculose generalizada e com extensas lesões no endométrio e miométrio de búfalos. Hein e Tomasovic ${ }^{41}$ em 1981, observaram 193 búfalos com lesões sugestivas de tuberculose durante a inspeção pos-mortem, três daquelas $(1,6 \%)$ com lesões no útero.

\section{Comentários Finais}

A tuberculose bovina é uma importante zoonose em todo mundo, de transmissão principalmente respiratória e também digestiva, cuja prevalência no Brasil em 1994 era estimada entre 0,9-2,9\%.42 Porém, não é caracterizada como doença da reprodução, ainda que a sua ocorrência no sistema reprodutivo de bovinos e bubalinos, machos e fêmeas, não seja tão rara.

Segundo Nocard e Leclainche ${ }^{26}$ (1903); Willians ${ }^{25}$ (1918); Vallée e Panisset ${ }^{27}$ (1920); Acha e Szyfres ${ }^{2}$ (1987), a tuberculose pode ser causa de alguns transtornos reprodutivos em fêmeas, como repetição de cio e infertilidade. Em machos, a infecção apresenta-se principalmente no pênis (glande), testículo e epidídimo, o que possibilita a transmissão via monta natural e inseminação artificial. Como citado por Roxo, ${ }^{1}$ a micobactéria pode persistir em ampolas de sêmen, o que o torna uma fonte importante de disseminação da tuberculose por inseminação artificial entre os animais. Salienta-se também o risco da introdução de receptoras de embrião com condição sanitária desconhecida e/ou 
sem diagnóstico tuberculínico prévio, servindo de fonte de infecção para outros bovinos.

Segundo Deshpande et al. ${ }^{35}$ (1966), a incidência de tuberculose nos búfalos é maior do que a encontrada em bovinos, e, neste estudo, foram encontradas lesões tuberculosas em vários órgãos, incluindo o aparelho reprodutor, como citado também por Polding e Lall ${ }^{39}$ (1945); Mandal e Singh ${ }^{40}$ (1975); e Hein e Tomasovic ${ }^{41}$ (1981).

No Brasil, a prevalência da tuberculose em bovinos é baixa, porém, não se tem esse parâmetro em búfalos. A tuberculose genital em bovinos e búfalos é pouco estudada atualmente, o que impossibilita avaliar a sua importância econômica no rebanho nacional. Todavia, deveria ser incluída no repertório de possibilidades e diagnóstico diferencial de possíveis causas de infertilidade em bovídeos domésticos.
Dessa forma, é necessário que os veterinários orientem os produtores, a fim de que animais positivos não sejam introduzidos no rebanho e que sejam eliminados todos os infectados, já que não há tratamento eficiente a ser indicado. Esses preceitos de teste-e-abate, bem como cuidados na introdução de novos animais no rebanho foram preconizados por Bang (apud ${ }^{27}$ ) no final do século XIX. Eles são a base de diversos programas sanitários bem-sucedidos no mundo, assim como do Programa Nacional de Controle e Erradicação de Brucelose e Tuberculose (PNCEBT), implantado pelo Ministério da Agricultura, Pecuária e Abastecimento (MAPA) em 2001. ${ }^{43}$ O principal objetivo do PNCEBT é diminuir o impacto nacional dessas duas zoonoses na saúde humana e animal, além de garantir a sanidade dos rebanhos e qualidade dos produtos de origem animal, visando mais à competitividade da pecuária nacional

\section{Abstract}

Objective: To present a review on genital tuberculosis in cattle and water buffaloes. Data Sources: the collections of the libraries of the Faculdade de Medicina Veterinária e Zootecnia da Universidade de São Paulo - FMVZUSP (School of Veterinary Medicine and Animal Science of the University of São Paulo) and of the Instituto Biológico de São Paulo (São Paulo Biological Institute), as well as MEDLINE database were searched, covering a retrospective period of 30 years. Data Synthesis: Tuberculosis is a public health concern and an economically important disease, responsible for big losses in cattle husbandry. The zoonotic aspect of tuberculosis has decreased since the introduction of obligatory milk pasteurization, except in countries where the consumption of raw milk and of cheese produced without any heat treatment still persists. It is estimated that $5 \%$ of tuberculous cows develop genital infection, manifested mostly as uterine lesions (metritis) and 1 to $2 \%$ can develop tuberculous mastitis. Genital tuberculosis is less frequent in males, but can affect most of the reproductive system. The incidence of tuberculosis is higher in water buffaloes than in cattle and all organs are affected, including the reproductive tract, where endometrial lesions occur. Conclusions: The estimated prevalence of bovine tuberculosis in Brazil is 0.9 to $2.9 \%$, but it is not considered a reproductive disease, although the affection of the reproductive system of cattle and buffaloes is not so rare, causing reproductive disorders such as infertility and estrus repetition, and representing a less common route of transmission of the disease.

Keywords: Tuberculosis, genital. Mycobacterium bovis. Infertility. Cattle. Buffaloes 
NASSAR, A. F. C.; ROXO, E.; PORTUGAL, M. A. S. C. Tuberculose genital. Genital tuberculosis. Tuberculosis genital. Rev. Educ. Contin. CRMV-SP / Contin. Educ. J. CRMV-SP, São Paulo, v. 8, n. 2, p. 135-144, 2005.

\section{Resumen}

Objetivo: Presentar una revisión sobre la tuberculosis genital en bovinos y búfalos. Fuentes Consultadas: Se consultaron los acervos de las bibliotecas de la Facultad de Medicina Veterinaria y Zootecnia de la Universidad de São Paulo (FMVZJUSP) y del Instituto Biológico de São Paulo, además de la base de datos MEDLINE, cuya consulta abarcó un periodo retrospectivo de 30 años. Síntesis de los Datos: La tuberculosis es una enfermedad de significativa importancia económica, causando grandes perjuicios en la pecuaria e implicaciones en salud pública. El aspecto zoonótico de la tuberculosis ha disminuido por la obligatoriedad de la pasteurización de la leche, pero en algunos países ese carácter de la enfermedad aún persiste por causa del hábito de consumir leche cruda y quesos producidos sin tratamiento térmico. Se estima que el 5\% de las vacas tuberculosas desarrollen infección genital, ocasionando principalmente lesiones en el útero (metritis) y que del 1 al 2\% puedan desarrollar mastitis tuberculosa. Tuberculosis genital en los machos es más rara, pero pueden ocasionar lesiones en prácticamente todo el aparato reproductivo. La incidencia de tuberculosis en búfalos es mayor que en bovinos, y las lesiones se concentran en todos los órganos incluyendo el sistema reproductivo con lesiones de endometrio. Comentarios Finales: Se estima que la prevalencia de la tuberculosis bovina en Brasil sea del 0.9 al 2,9\%, pero no se la caracteriza como enfermedad reproductiva, aunque su ocurrencia no sea tan rara en el sistema reproductivo de bovinos y bufalinos, causando disturbios reproductivos, como infertilidad y repeticiones de celo, representando así una vía poco común de transmisión de la enfermedad.

Palabras-clave: Tuberculosis de los genitales. Mycobacterium bovis. Infertilidad. Bovinos. Búfalos.

\section{Referências}

1. ROXO, E. Tuberculose bovina: revisão. Arquivos do Instituto Biológico, São Paulo, v. 63, p. 91-97, 1996.

2. ACHA, P. N; SZYFRES, B. Zoonotic tuberculosis. In:___ Zoonoses and communicable diseases common to man and animals. 2. ed. Washington: Pan American Health Organization, 1987. (Scientific Publication, n. 503, p. 174-185, 1987).

3. COLlins, F. M. The immune response to mycobacterial infection: development of new vaccines. Veterinary Microbiology, v. 40, p. 95110, 1994.

4. COUSINS, D. V. et al. Use of DNA amplification for the rapid identification of Mycobacterium bovis. Veterinary Microbiology, v. 27, p. 187-195, 1991.

5. DABORN, C. J.; GRANGE, J. M. COSIVI, O. HIV/ AIDS and its implications for control of animal tuberculosis. European Respiratory Journal, v. 7, p. 1567-6, 1994.
6. KOVALYOV, G. K. On human tuberculosis due to M. bovis: a review. Journal Hygiene Epidemiology Microbiology Immunology, v. 33, p. 199-206, 1989.

7. ZACARÍAS, F. et al. HIV/AIDS, and its interaction with tuberculosis in Latin America and the Caribbean. Bulletin Panamerican American Health Organization, v. 28, p. 312-323, 1994.

8. LEITE, C. Q. F.; TELAROLLI JÚNIOR, R. Aspectos epidemiológicos a clínicos da tuberculose. Revista da Faculdade de Ciências Farmacêuticas, São Paulo, v. 18, p. 17-28, 1997.

9. CORRÊA, W. M.; CORRÊA, C. N. M. Enfermidades infecciosas dos animais domésticos. São Paulo: Varela, 1983. 823 p

10. ROTHSCHILD, B. M. et al. Mycobacterium tuberculosis complex DNA from an extinct bison dates 17.000 years before the present. Clinical and Infections Disease, v. 33, p.305-311, 2001. 
11. $\mathrm{KOCH}, \mathrm{R}$. Die atiologie der tuberkulose. Berliner Klinischen Wochenschrift, v. 15, p. 221-230, 1882.

12. PRITCHARD, D. G. A century of bovine tuberculosis 1888-1988: conquest and controversy. Journal of Comparative Pathology, v. 99, p. 357-99, 1988.

13. FERREIRA NETO, J. S.; BERNARDI, F. O controle da tuberculose bovina. Higiene Alimentar, v. 11, p.9-13, 1997.

14. DANKNER, W. M. et al. Mycobacterium bovis infections in San Diego: a clinicoepidemiologic study of 73 patients and a historical review of a forgotten pathogen. Medicine Baltimore, v. 72, p. 11-37, 1993.

15. BIER, O. Micobactérias. In:__. Bacterologia e imunologia. 19. ed. São Paulo, Edições Melhoramentos, 1978. p. 585-610.

16. TRABULSI, L. R. et al. Microbiologia. 3. ed. São Paulo: Atheneu, 2002. 586 p.

17. ARANAZ, A. et al. Spacer oligonucleotide typing of Mycobacterium bovis strains from cattle and other animals: a tool for studying epidemiology of tuberculosis. Journal Clinical Microbiology, v. 34, p. 2734-40, 1996.

18. ABRAHÃO, R. M. C. Tuberculose humana causada pelo Mycobacterium bovis: considerações gerais e a importância dos reservatórios animais. Archives Veterinary Science, v. 4, p. 5-15, 1999.

19. COUSINS, D. V. et al. Tuberculosis in seals caused by a novel member of the Mycobacterium tuberculosis complex: Mycobacterium pinnipedii sp. nov. International Journal of Systematic and Evolutionary Microbiology, v. 53, p. 1305-1314, 2003.

20. NEILL, S. D. et al. Pathogenesis of Mycobacterium bovis infection in cattle. Veterinary Microbiology, v. 40, p. 41-52, 1994.

21. YOUMANS, G. P. Tuberculosis. Philadelphia: Saundres, 1979. $511 \mathrm{p}$.

22. BRUNINI SOBRINHO, R. Tuberculose no homem e nos animais. Casa da Agricultura, v. 10, n. 2, p. 17-8, 1988.
23. THOMPSON, P. J. et al. Seals, seal trainers, and Mycobacterial infections. American Review Respiratory Disease, v. 147, p. 167-7, 1993.

24. THOREL, M. F. ; MOUTOU, F. Tuberculose et animaux sauvages. Point Vétérinaire, v. 26, n. 159, p. 27-34, 1994.

25. WILLIAMS, L. W. Genital tuberculosis of catlle. Journal of the American Veterinary Medical Association, v. 4, p. 29-63, 1918.

26. NOCARD, E.; LECLAINCHE, E. Les maladies microbiennes des animaux. 3. ed. Paris: Masson, 1903. v. 2, p. 1-155.

27. VALLÉE, H.; PANISSET, L. Les tuberculoses animales. Paris: Octave Doin, 1920. 528 p.

28. PETISCA, J. L. N. Patologia e anatomia patológica da tuberculose dos bovinos e dos suínos. Veterinária Moçambicana, v. 1, p. 117-135, 1969.

29. NIYAZ AHMED, A. S.; KHAN, J. R.; GANAI, N.A. DNA amplification assay for rapid detection of bovine tubercle bacilli in semen. Animal Reproduction Science, v. 57, p. 15-21, 1999.

30. MAnninger, R.; MÓCSY, J. Patología y terapéutica especiales de los animales domésticos. Barcelona: Labor, 1973. v. 2.

31. MYERS, J. A. Man's greatest victory over tuberculosis. Baltimore: Thomas Books, 1940. 419 p.

32. ROXO, E.; ALBERTI, H.; ALBERTI, A. L. L. Ocorrência de tuberculose avançada em bezerro. Arquivos do Instituto Biológico, São Paulo, v. 57, p. 74, 1990. Suplemento.

33. PINTO,C. Doenças infecciosas e parasitárias dos animais domésticos. Rio de Janeiro: Scientífica; 1944. $756 \mathrm{p}$.

34. BURROWS, H. Some aspects of bovine tuberculosis. Veterinary Journal, v. 93, p. 44-48, 1937.

35. DESHPANDE, B. R.; SARDESHPANDE, P. D.; SANE, C. R. Tuberculous endometritis in a buffalo cow. Indian Veterinary Journal, v. 43, p. 288291, 1966. 
36. ELWISBY, A. B. A preliminary study of the genital organs of indigenous cows in Uganda. Beiträge Tropical Landwirtsch Veterinärmed, v. 14, p. 95107, 1976.

37. BIOLATTI, B.; PAU, S.; GALLONI, M. The epithelial pathology of bovine genital tuberculosis Journal of Comparative Pathology, v. 100, p. 137-144, 1989.

38. ROXO, E.; DIAS, B. C.; PORTUGAL, M. A. S. C. Tuberculose genital em bovinos. In: CONGRESSO BRASILEIRO DE MICROBIOLOGIA, 17., 1993, Santos, SP. Resumos... São Paulo: Sociedade Brasileira de Microbiologia, 1993. p. 170.

39. POLDING, J. B.; LALL, H. K. Some genital abnormalites of the indian cow and buffalo, with reference to anatomical differences in their reproductive organs. Indian Journal of Veterinary Science and Animal Husbandry, v. 15, p. 178-182, 1945.
40. MANDAL, P. C.; SINGH, B. Tuberculous metritis in a buffalo (Bubalus Bubalis). Indian Journal of Animal Health, v. 45, p. 121-122, 1975.

41. HEIN, W. R.; TOMASOVIC, A. A. An abattoir survey of tuberculosis in feral buffaloes. Australian Veterinary Journal, v. 57, p. 543-547, 1981.

42. KANTOR, I. N.; RITACCO, V. Bovine tuberculosis in Latin America and the Caribean: current status, control and eradication programs. Veterinary Microbiology, v. 40, p. 5-14, 1993.

43. MINISTÉRIO DA AGRICULTURA, PECUÁRIA E ABASTECIMENTO. Programa Nacional de Controle e Erradicação de Brucelose e Tuberculose (PNCEBT). Brasília, 2005. Disponível em: <http:/ /www.agricultura.gov.br>. Acesso: 30 jun. 2005.

Endereço Address Dirección:

Dra. Alessandra Figueiredo de Castro Nassar

Instituto Biológico

Av. Cons. Rodrigues Alves, 1252

Caixa Postal 12.898

CEP: 04014-002 - São Paulo, SP, Brasil

Tel.: (0xx) 11 5087-1774/

Fax: (0xx) 11 5087-1791

E-mail: nassar@biologico.sp.gov.br 